\title{
Fungal and Viral Oral Infections in individuals with Onco-Hematologic Neoplasms in a University Hospital
}

\author{
Thaiane Dantas Dias dos Santos, ${ }^{1}$ Patrícia Leite Ribeiro, ${ }^{2}$ Renata Portela de Rezende, ${ }^{1}$ Davi Silva Carvalho Curi, ${ }^{3}$ \\ João Frank Carvalho Dantas de Oliveira, ${ }^{4}$ Viviane Almeida Sarmento ${ }^{5}$ \\ ${ }^{1}$ Student of Federal University of Bahia Postgraduate Program in Dentistry \\ ${ }^{2}$ Doctor, Associate professor of Dentistry College of Federal University of Bahia \\ ${ }^{3}$ Student of Federal University of Pernambuco Postgraduate Program in Child and Adolescent Health \\ ${ }^{4}$ Post doctor, Assistant teacher of Dentistry College of Federal University of Bahia \\ ${ }^{5}$ Post doctor, Associate professor of Dentistry College of Federal University of Bahia
}

\begin{abstract}
Introduction: Individuals undergoing onco-hematologic treatment present higher risk for developing oral and/or systemic infections, due to the intense immunosuppression and compromise of the mucosal barriers during treatment. The aim of this study was to identify the fungal and viral oral infections that most frequently affected patients undergoing onco-hematologic treatment in a University Hospital, and relate them to the biopsychosocial data, underlying disease and treatment. Methods: This was a crosssectional study in which descriptive analysis of the data was performed, and the Exact Fisher test was applied to verify the association between the infections and the variables: sex, age group, educational level, underlying disease and treatment, considering a $5 \%$ probability of error. Results and Discussion: The clinical exam revealed that oral candidiasis was present in $8.92 \%$ of the individuals, and herpes simplex, in $4.5 \%$. No significant associations were found between the variables and infections. The fungal and viral oral infections were little prevalente in individuals with hematologic neoplasms in the present study, suggesting that the action of dental surgeons in caring for the onco-hematologic patients at the Institution evaluated and the protocols use were efficient.
\end{abstract}

Keywords: hematological diseases, oral candidiasis, herpes simplex.

Received for publication: May 03, 2017 Accepted: June 15, 2017

Correspondence to:

Thaiane Dantas Dias dos Santos Address: Rua Maria dos Reis Silva n²12, Loteamento Miragem, Lauro de Freitas, Bahia,

Brasil. 42.700-000.

Telephone: +55 (71) 99276-8390

e-mail: thaianedantas@yahoo.com.br

\section{Introduction}

Oral health care must be included in the treatment of individuals with oncohematologic neoplasms, since they may present deficient oral hygiene or infectious foci that predispose them to higher risk of developing oral and/or systemic infections when submitted to chemotherapy and/or bone marrow transplantation (BMT) ${ }^{1-3}$. Furthermore, oral manifestations resulting from the direct action of onco-hematologic therapy on the oral tissues, or indirectly due to immunosuppression may increase the risk of mortality, time of hospitalization and treatment costs ${ }^{3-5}$.

Among the oral manifestations caused by immunosuppression, fungal and viral infections are outstanding, especially candidiasis and herpes simplex, respectively. 
Candidiasis normally presents in the pseudomembranous ${ }^{6}$ form, with formation of whitened, scrapable plaques on the oral mucosa, capable of causing the patient discomfort. Topical antifungal agents, such as Nystatin, are the first line of treatment for candidiasis ${ }^{7,8}$, however, systemic antifungal medications are more effective in immunosuppressed individuals ${ }^{8}$.

In relation to viral infections, immunosuppression may reactivate latent viral infections, generally with more serious atypical signs than those manifesting in immunocompetent patients $^{9,10}$. In the oral mucosa, herpes simplex is the most common viral infection, characterized by the formation of vesicles that rupture and form painful ulcers in the oral cavity and oropharyn $\mathrm{x}^{11}$. The use of systemic antiviral agents such as Aciclovir and Valaciclovir, is indicated for prophylaxis and treatment of these lesions ${ }^{12}$, in addition to complementary therapies, used for pain relief and reduction in the period of clinical manifestation, such as laser photobiomodulation ${ }^{13}$.

The authors therefore suggest the inclusion of the Dental Surgeon (DS) in the multiprofessional team that cares for individuals with onco-hematologic neoplasms to prevent, diagnose and treat these manifestations, with a view to minimizing suffering and improve the quality of life during oncological treatment. Nevertheless, there is a scarcity of studies that show the frequency of these infections in centers with the presence of the dental surgeon.

Therefore, the aim of this study was to evaluate the frequency of fungal and viral oral infections in individuals submitted to onco-hematologic treatment, in a University Hospital, and associated them with the age, sex, educational level, underlying disease and oncological treatments performed. The hypothesis tested was that the frequency of these infections would be low, irrespective of the sociodemographic factors, disease and oncological treatment instituted, due to the regular dental care offered to this group of patients.

\section{Methods}

This was an observational, cross-sectional, descriptive and quantitative study approved by CEP/HUPES (CAEE 1.158.496). Included in the study were individuals undergoing oncohematologic treatment in a public university hospital, followedup by the dental service of the same hospital, in the period from November, 2013, to February, 2016, who accepted to participate in this research by signing the Term of Free and Informed Consent. The patients who did not wish to participate, and those who were in a physical condition to undergo the dental exam were excluded from the sample.

Identification data were collected and registered (age, gender and educational level), in addition to information about the underlying disease (diagnosis and treatment instituted) and subsequently the intraoral exam was performed with a dental mirror and oral retractors, under lighting suitable for identifying lesions of fungal or viral origin.

The data of patients who had been discharged from hospital, or who were already being followed-up by the dental service prior to the research were collected from secondary sources (record chart, clinical chart from the Dental Service).

All the patients received the necessary care suited to their oral requirements, including guidance on diet and oral hygiene, elimination of infectious foci and control of oral biofilm. Moreover, they continued to receive dental follow-up or treat possible oral complications.

Descriptive analysis of the data was performed, and the mean and frequency were calculated. In addition the Exact Fisher test was used to verify the association between the infections and the variables: sex, age group, educational level, underlying disease and treatment, considering a $5 \%$ probability of error.

\section{Results}

Considering the eligibility criteria, 112 individuals with onco-hematologic neoplasms formed part of the sample. In relation to educational level, 40 individuals had no records, and analysis was performed in the 72 remaining individuals.

Table 1 shows the sociodemographic characteristics, underlying disease, oncological treatment instituted, and those of the oral infections of the sample. Of these, 54 (48.2\%) were of the male sex and $58(51.8 \%)$ were women. Their ages ranged from 15 to 85 years, with a mean age of $41.08(+17.26)$ years, and there was discrete predominance of the age group 43-54 years. Of the 72 individuals who had records of schooling, those who had up to 8 years of schooling $(45.8 \%)$ predominated, followed by those we were from nine to 11 years of schooling (41.7\%) (Table 1).

Table 1 - Sociodemographic characteristics of the base disease of the oncological treatment instituted, and the oral infections in onco-hematologic individuals at HUPES/UFBA, Salvador, Brazil, 2013-2016.

\begin{tabular}{lcc}
\hline Categorical Variables & N & $\%$ \\
\hline Age & & \\
15-24 years & 28 & 25.0 \\
25-42 years & 27 & 24.1 \\
$43-54$ years & 30 & 26.8 \\
>54 years & 27 & 24.1 \\
Sex & & \\
Male & 54 & 48.2 \\
Female & 58 & 51.8 \\
Educational level & \\
Up to 08 years & 33 & 45.8 \\
9-11 years & 30 & 41.7 \\
$>11$ years & 09 & 12.5 \\
Underlying Disease: & & \\
Acute Leukemias & & 8.9 \\
Chronic Leukemias & 10 & 24.1 \\
Lymphomas & 27 & 28.6 \\
Multiple Myeloma & 32 & 1.8 \\
MDS & 02 & \\
Oncological Treatment & & 55.4 \\
QTx alone & 62 & 35.7 \\
QTx+ other treatments & 40 & 8.9 \\
BMT alone & 10 & 86.6 \\
Oral Infections & & 4.5 \\
Without infections & 97 & \\
Candidiasis & 10 & \\
Herpes simplex & 05 & \\
\hline
\end{tabular}

a The absolute and relative frequencies of this variable were calculated for 72 individuals. The 40 remaining subjects had no record of schooling. $\mathrm{MDS}=$ myelodysplastic syndrome; $\mathrm{QTx}=$ Chemotherapy; $\mathrm{BMT}=\mathrm{Bone}$ Marrow transplant. 
In relation to the underlying disease, acute leukemias $(36.6 \%)$ and multiple myeloma $(28.6 \%)$ were the most frequent onco-hematologic neoplasms, respectively. As regards the oncological treatment instituted, the majority of the individuals were submitted to chemotherapy alone $(55.4 \%)$. In relation to the fungal and viral oral infections, candidiasis was present in $8.92 \%$ of the individuals, and herpes simplex in 5,35\% (Table 1).
Table 2 shows the association between oral candidiasis, age, sex, educational level, underlying disease and oncological treatment instituted. There were a higher number of cases in the age group from $15-24$ years $(50 \%)$, in the female sex $(60 \%)$ and in individuals who had between nine and 11 years of schooling (57.1\%), however, without statistically significant difference for the three variables $(p>0.05)$.

Table 2 - Association between oral candidiasis and age, sex, educational level, underlying disease and oncological treatment instituted in onco-hematologic individuals of HUPES/UFBA, Salvador, Brazil, 2013-2016.

\begin{tabular}{|c|c|c|c|c|c|}
\hline \multirow{3}{*}{ Independent Variables } & \multicolumn{4}{|c|}{ Oral Candidiasis } & \multirow{3}{*}{$p^{a}$} \\
\hline & \multicolumn{2}{|c|}{ Yes $(n=10)$} & \multicolumn{2}{|c|}{ No $(n=102)$} & \\
\hline & $\mathrm{N}$ & $\%$ & $\mathrm{n}$ & $\%$ & \\
\hline \multicolumn{6}{|l|}{ Age } \\
\hline $15-24$ years & 5 & 50.0 & 23 & 22.5 & \multirow{4}{*}{0.35} \\
\hline $25-42$ years & 2 & 20.0 & 25 & 24.5 & \\
\hline $43-54$ years & 2 & 20.0 & 28 & 27.5 & \\
\hline$>54$ years & 1 & 10.0 & 26 & 25.5 & \\
\hline \multicolumn{6}{|l|}{ Sex } \\
\hline Male & 4 & 40.0 & 50 & 49.0 & \multirow{2}{*}{0.41} \\
\hline Female & 6 & 60.0 & 52 & 51.0 & \\
\hline \multicolumn{6}{|l|}{ Educational level| ${ }^{b}$} \\
\hline Up to 08 years & 3 & 42.9 & 30 & 46.2 & \multirow{3}{*}{0.64} \\
\hline $9-11$ years & 4 & 57.1 & 26 & 40.0 & \\
\hline$>11$ years & 0 & 0.0 & 09 & 13.8 & \\
\hline \multicolumn{6}{|l|}{ Underlying Disease: } \\
\hline Acute Leukemias & 2 & 20.0 & 39 & 38.2 & \multirow{5}{*}{0.10} \\
\hline Chronic Leukemias & 2 & 20.0 & 08 & 7.8 & \\
\hline Lymphomas & 5 & 50.0 & 22 & 21.6 & \\
\hline Multiple Myeloma & 1 & 10.0 & 31 & 30.4 & \\
\hline MDS & 0 & 0.0 & 02 & 2.0 & \\
\hline \multicolumn{6}{|l|}{ Oncological Treatment } \\
\hline QTx alone & 7 & 70.0 & 55 & 53.9 & \multirow{3}{*}{0.68} \\
\hline QTx + other treatments & 3 & 30.0 & 37 & 36.3 & \\
\hline BMT & 0 & 0.0 & 10 & 9.8 & \\
\hline
\end{tabular}

MDS $=$ myelodysplastic syndrome QTx $=$ Chemotherapy BMT $=$ Bone Marrow transplant.

${ }^{a}$ Exact Fisher Test Level of significance $\mathrm{p}<0.05$.

${ }^{b}$ The absolute and relative frequencies of this variable were calculated for 72 individuals. The 40 remaining subjects had no record of schooling.

In relation to the underlying disease, oral candidiasis was most frequent in those with diagnosis of lymphoma (5), although without statistically significant difference $(p>0.05)$. As regards the oncological treatment instituted, the majority of individuals who developed candidiasis received only chemotherapy, however, without statistically significant difference $(p>0.05)$ (Table 2).

Table 3 shows the association between herpes simplex, age, sex, educational level, underlying disease and oncological treatment instituted. This infection was more frequent in the female sex although there was no statistically significant difference $(p>0.05)$. There was no predilection for age group and educational level ( $\mathrm{p}>0.05)$, but the individuals from 15-24 years $(40.0 \%)$ and $25-42$ years $(40.0 \%)$ and those who had up to eight years of schooling (50\%) and between nine and 11 years of schooling $(50 \%)$ were those most affected.

In relation to the underlying disease, herpes simplex was most frequent in those with diagnosis of multiple myeloma (40\%), and acute leukemias (40\%) although without statistically significant difference $(p>0.05)$. As regards the oncological treatment instituted, the majority of individuals who had herpes simplex received chemotherapy associated with other therapies ( $60 \%)$, followed by those who were submitted to chemotherapy alone (40\%), however, not presenting any statistically significant difference $(p>0.05)$ (Table 3$)$. 
Table 3 - Association between herpes simplex and age, sex, educational level, underlying disease and oncological treatment instituted in onco-hematologic individuals of HUPES/UFBA, Salvador, Brazil, 2013-2016.

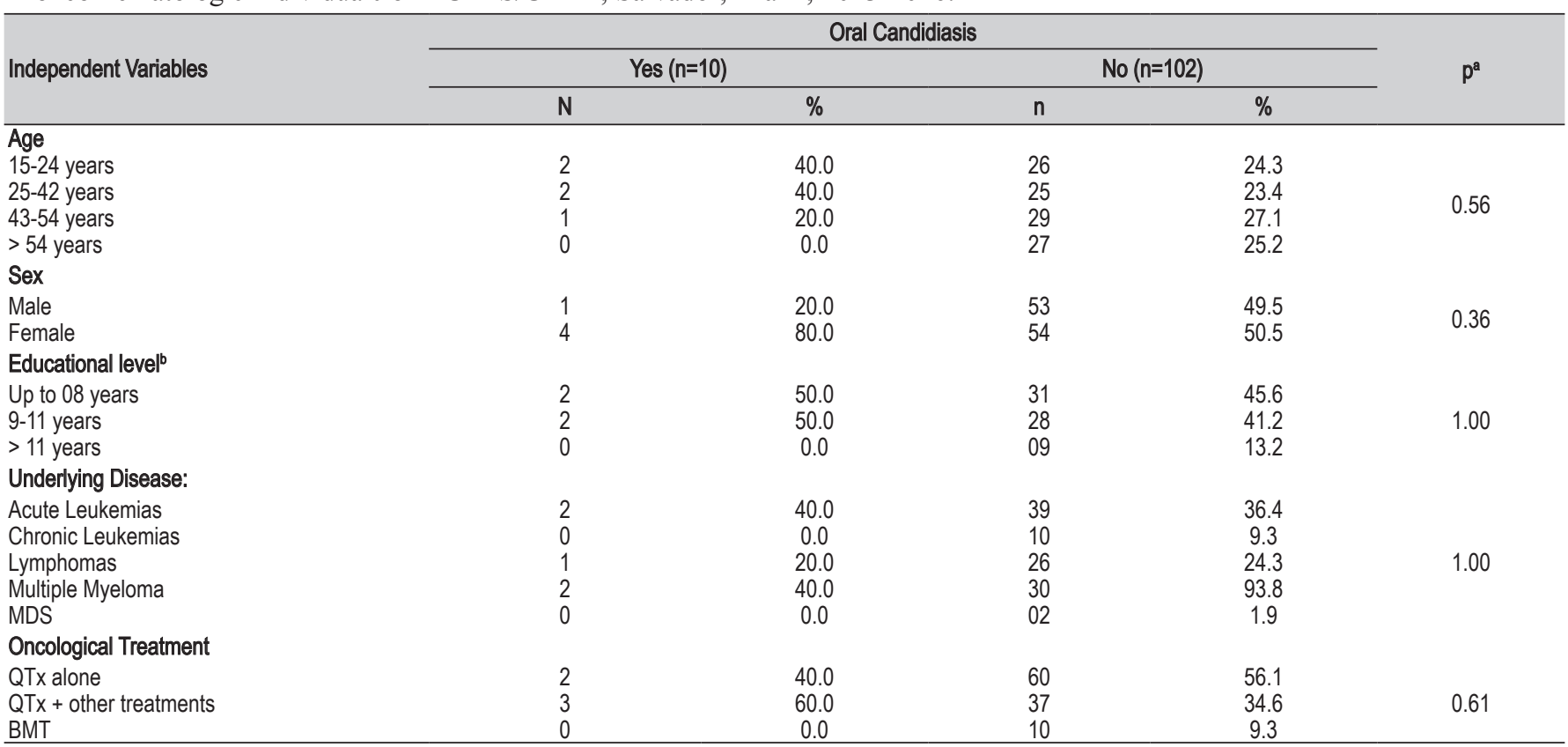

MDS $=$ myelodysplastic syndrome; $\mathrm{QTx}=$ Chemotherapy BMT $=$ Bone Marrow transplant.

${ }^{a}$ Exact Fisher Test Level of significance $\mathrm{p}<0.05$.

${ }^{b}$ The absolute and relative frequencies of this variable were calculated for 72 individuals. The 40 remaining subjects had no record of schooling.

\section{Discussion}

Individuals undergoing onco-hematologic therapy are more susceptible to viral, bacterial and fungal infections, due to the intense immunosuppression and compromise of mucosal barriers $^{1-3}$, in addition to quantitative and qualitative changes in the oral microbioma, capable of occurring in over $70 \%$ of immunosuppressed patients ${ }^{14}$.

In the present study, only 15 individuals (13.4\%) presented fungal or viral infections. This low rate may be explained by the infectious prophylaxis protocols instituted by the Oncohematologic Service and by the dental care that patients receive during antineoplastic treatment. At this treatment center, in addition to receiving adequate oral hygiene guidance, patients are submitted to dental procedures suited to the oral medium, such as removal of root remainders, root scaling and planing, endodontic treatment, carious tissue removal and dental cavity sealing. These actions effectively tend to reduce the pathogenic oral microbioma and possibly influenced the results here observed.

Among the viral infections in the oral mucosa, infection by the herpes simplex virus (HSV) has been pointed out as the most common in immunocompromised patients. The reactivation of HSV affected up to $80 \%$ of the patients with hematological diseases before the use of antiviral prophylaxis ${ }^{15}$. The labial region most frequently being affected, followed by the keratinized mucosas, such as the palate, dorsum of the tongue and gingiva ${ }^{16}$.
In the study of Gomez et al. ${ }^{17}$ (2001) the incidence of HSV in patients who were submitted to BMT was $26.9 \%$. In the present study infection by the HSV affected only $4.5 \%$ of the individuals. This frequency was low, compared with those of other studies ${ }^{10,17}$, suggesting that the prophylactic regimes for viral infections ${ }^{15}$, adopted at the institution evaluated were effective. These prophylactic regimes may vary according to the underlying disease, chemotherapy regime and patient's clinical condition. However, in general, the antiviral prophylaxis used by the Service consists of the administration of Aciclovir, beginning concomitantly with chemotherapy treatment. These findings corroborated controlled clinical trial studies with the use of Aciclovir in patients with hematologic diseases, in whom a reduction of $80-90 \%$ in risk of infection by HSV was observed ${ }^{12,18}$

In relation to fungal infections it is known that in individuals with leukopenia due to myelosuppression, the main fungal infection were caused by Candida albicans, resulting not only from neutropenia, but also from the use of broad spectrum antibiotics and inadequate oral hygiene ${ }^{19}$. This susceptibility increased when medications with high aggressive potential against the defense cells and oral mucosa cells are administered, such as chemotherapy drugs that induce epithelial changes and will favor the adhesion and proliferation of the microorganism ${ }^{20}$.

In the study of Xu et al. ${ }^{21}$ (2013) oral candidiasis affected $52 \%$ of the 850 patients studied, while in the present study candidiasis was present in only $8.9 \%$ of the patients. This difference may be explained by the fact that in the cited study, 
the author affirmed that the patients were in an advanced stage of the disease, with inadequate nutritional and oral hygiene status, whereas in the present study, the patients were on nutritional support therapy, antifungal prophylaxis with a systemic antifungal agent ${ }^{22}$, received oral hygiene instructions and underwent dental follow-up during antineoplastic therapy, therefore presenting adequate oral hygiene.

In view of the findings, the authors perceived that the presence of the dental surgeon in the care of individuals with onco-hematologic neoplasms was related to a low frequency of fungal and viral infections, irrespective of the sociodemographic factors, disease and oncological treatment instituted. This guaranteed prevention, diagnosis and early treatment of infections and other complications secondary to the neoplasm and oncological treatment.

\section{References}

1. Rizzo JD, Wingard JR, Tichelli A, Lee SJ, Van Lint MT, Burns LJ, et al. Recommended screening and preventive practices for long-term survivors after hematopoietic cell transplantation: joint recommendations of the European Group for Blood and Marrow Transplantation, the Center for International Blood and Marrow Transplant Research, and the American Society of Blood and Marrow Transplantation. Biol Blood Marrow Transplant. 2006 Feb;12(2):138-51.

2. McGuire DB, Correa MEP, Johnson J, Wienandts P. The role of basic oral care and good clinical practice principles in the management of oral mucositis. Support Care Cancer. 2006 Jun;14(6):541-7.

3. Brennan MT, Elting LS, Spijkervet FKL. Systematic reviews of oral complications from cancer therapies, Oral Care Study Group, MASCC/ ISOO: methodology and quality of the literature. Support Care Cancer. 2010 Aug;18(8):979-84. doi: 10.1007/s00520-010-0856-3.

4. Majorana A, Schubert MM, Porta F, Ugazio AG, Sapelli PL. Oral complications of pediatric hematopoietic cell transplantation: diagnosis and management. Support Care Cancer. 2000 Sep;8(5):353-65.

5. Da Silva Santos PS, Guaré RO, Fachin LV, Correa MSNP. [Bone marrow transplant: general considerations and oral manifestations in pediatric patients]. Rev Assoc Paul Cir Dent. 2008;62(6):450-4. Portuguese.

6. Lalla RV, Latortue MC, Hong $\mathrm{CH}$, Ariyawardana A, D'Amato-Palumbo S, Fischer DJ, et al. A systematic review of oral fungal infections in patients receiving cancer therapy. Support Care Cancer. 2010 Aug;18(8):985-92. doi: 10.1007/s00520-010-0892-z.

7. Gligorov J, Bastit L, Gervais H, Henni M, Kahila W, Lepille D, et al. Prevalence and treatment management of oropharyngeal candidiasis in cancer patients: results of the French CANDIDOSCOPE study. Int J Radiat Oncol Biol Phys. 2011 Jun 1;80(2):532-9. doi: 10.1016/j. ijrobp.2010.02.006.

8. Reboli AC, Shorr AF, Rotstein C, Pappas PG, Kett DH, Schlamm HT, et al. Anidulafungin compared with fluconazole for treatment of candidemia and other forms of invasive candidiasis caused by Candida albicans: a multivariate analysis of factors associated with improved outcome. BMC
Infect Dis. 2011 Sep 30;11:261. doi: 10.1186/1471-2334-11-261.

9. Gürgan CA, Özcan M, Karaku ş Ö, Zincircio ğlu G, Arat M, Soydan $\mathrm{E}$, et al. Periodontal status and post Itransplantation complications following intensive periodontal treatment in patients underwent allogenic hematopoietic stem cell transplantation conditioned with myeloablative regimen. Int J Dent Hyg. 2013 May;11(2):84-90. doi: 10.1111/j.16015037.2012.00550.x.

10. Palmason S, Marty FM, Treister NS. How do we manage oral infections in allogeneic stem cell transplantation and other severely immunocompromised patients? Oral Maxillofac Surg Clin North Am. 2011 Nov;23(4):579-99, vii. doi: 10.1016/j.coms.2011.07.012.

11. Chen YK, Hou HA, Chow JM, Chen YC, Hsueh PR, Tien HF. The impact of oral herpes simplex virus infection and candidiasis on chemotherapyinduced oral mucositis among patients with hematological malignancies. Eur J Clin Microbiol Infect Dis. 2011 Jun;30(6):753-9. doi: 10.1007/ s10096-010-1148-z.

12. Glenny AM, Fernandez Mauleffinch LM, Pavitt S, Walsh T. Interventions for the prevention and treatment of herpes simplex virus in patients being treated for cancer. Cochrane Database Syst Rev. 2009 Jan 21;(1):CD006706. doi: 10.1002/14651858.CD006706.pub2.

13. Bello-Silva MS, de Freitas PM, Aranha AC, Lage-Marques JL, Simões A, de Paula Eduardo C. Low-and high-intensity lasers in the treatment of herpes simplex virus 1 infection. Photomed Laser Surg. 2010 Feb;28(1):135-9. doi: 10.1089/pho.2008.2458.

14. Naylor GD, Marino GG, Shumway RC. Glossodynia after radiation therapy and chemotherapy. Ear Nose Throat J. 1989 Oct;68(10):751-7.

15. Teh BW, Slavin MA, Harrison SJ, Worth LJ. Prevention of viral infections in patients with multiple myeloma: the role of antiviral prophylaxis and immunization. Expert Rev Anti Infect Ther. 2015;13(11):1325-36. doi: 10.1586/14787210.2015.1083858

16. Neville BW, Damm DD, Chi AC, Allen CM. Oral and maxillofacia pathology. Saint Louis: Elsevier Health Sciences; 2015.

17. Gomez RS, Carneiro MA, Souza LN, Victória JM, de Azevedo WM, De Marco L, et al. Oral recurrent human herpes virus infection and bone marrow transplantation survival. Oral Surg Oral Med Oral Pathol Oral Radiol Endod. 2001 May;91(5):552-6.

18. Yahav D, Gafter-Gvili A, Muchtar E, Skalsky K, Kariv G, Yeshurun M, et al. Antiviral prophylaxis in haematological patients: systematic review and meta-analysis. Eur J Cancer. 2009 Dec;45(18):3131-48. doi: 10.1016/j. ejca.2009.08.010.

19. Braunwald, E, Harrison TR. Harrison's principles of internal medicine. 2001. New York: McGraw-Hill Professional Publishing; 2001. v.1.

20. Soysa NS, Samaranayake LP, Ellepola ANB. Cytotoxic drugs, radiotherapy and oral candidiasis. Oral Oncology. 2004 Nov;40(10):9718.

21. Xu L, Zhang H, Liu J, Chen X. Investigation of the oral infections and manifestations seen in patients with advanced cancer. Pak J Med Sci. 2013 Sep;29(5):1112-5

22. Tacke D, Buchheidt D, Karthaus M, Krause SW, Maschmeyer G, Neumann S, et al. Primary prophylaxis of invasive fungal infections in patients with haematologic malignancies. 2014 update of the recommendations of the Infectious Diseases Working Party of the German Society for Haematology and Oncology. Ann Hematol. 2014 Sep;93(9):1449-56. doi: 10.1007/s00277-014-2108-y. 